\title{
ASSESSMENT OF ECONOMIC EFFICIENCY AND RISK OF THE PROJECT USING SIMULATION
}

\author{
Janekova, J. ; Fabianova, J. ${ }^{* *} \&$ Fabian, M. ${ }^{* * *}$ \\ *Institute of Management, Industrial and Digital Engineering, Faculty of Mechanical Engineering, \\ Technical University of Kosice, Park Komenskeho 9, 04200 Kosice, Slovakia \\ ${ }^{* *}$ Institute of Logistics, Faculty of Mining, Ecology, Process Control and Geotechnology, \\ Technical University of Kosice, Letna 9, 04200 Kosice, Slovakia \\ *** Department of Automotive Production, Technical University of Kosice, Mäsiarska 74, \\ 04200 Kosice, Slovakia \\ E-Mail: jaroslava.janekova@tuke.sk, jana.fabianova@tuke.sk, michal.fabian@tuke.sk
}

\begin{abstract}
The article aimed to present an approach to assessment of economic efficiency and risk of the investment project using Monte Carlo simulation. In this case study, post-audit was presented after $4^{\text {th }}$ year of investment operation. A multilevel post-audit was conducted by combining economic efficiency assessment and the Monte Carlo simulation technique. In the first phase, the most serious factors causing Discounted Economic Value Added (DEVA) deviation from the planned value were identified. In the second step, the correction of the selected input variables, and calculation of the corrected indicator DEVA were performed. The third step was forecasting the DEVA indicator conducted by Monte Carlo simulation. Simulation results were used for assessing the critical factors and their impacts on the DEVA indicator. In the end, on the basis of analyses, calculations and simulations, the results were compared, and the relevance of the presented methodology for practice was discussed.

(Received in October 2018, accepted in January 2019. This paper was with the authors 2 weeks for 1 revision.)
\end{abstract}

Key Words: Project Management, Post-Audit, Risk Analysis, Monte Carlo Simulation

\section{INTRODUCTION}

In current conditions of rapid change and uncertainty, project success is determined by risk management. For costly projects, risk management is a necessary part of the overall project management process [1]. Monitoring of risks, financial indicators and their deviations from their planned values is neglected mostly in the implementation phase of the project. Post audit and controlling are effective risk management tools in the final stages of the project. Azzone and Maccarrone [2] focused on the possible benefits and problems generated by the implementation of a post-auditing system. The post-audit study of Soares et al. [3] concerned the accuracy of capital budgeting procedures. It was based on the statistical analysis of the deviations between effective and forecasted performance of companies. Sandström et al. [4] considered unifying the processes of planning, management, and post-audit into one dynamic investment profitability management process. Application of the deviation analysis method in the utilisation phase of the investment project was performed at the study by Janekova et al. [5]. Lendo-Siwicka et al. [6] presented the result of a risk analysis made after completion of the investment project and accepting it for use.

The most important phase in risk management is the identification and risk analysis phase. Proper detection and risk assessment is the starting point for choosing appropriate measures. Results of research and experiences in the field of risk analysis are described by several authors. Event-tree (ET) or fault-tree (FT) methodology is the most popular approach to probability risk assessment. Suresh et al. [7] presented a comparative study of probabilistic and fuzzy methodologies for top event uncertainty evaluation in fault-tree analysis. A methodology that combined Markov modelling with the cell-to-cell mapping technique to 
construct dynamic ET/FT was presented by Bucci et al. [8]. In dynamic fault-tree analysis, Markov models were used also by Durga Rao et al. [9] in solving dynamic gates. A methodology for a fuzzy based computer-aided fault-tree analysis tool was published by Ferdous et al. [10]. In the paper by Ejlali and Miremadi [11], a tree model, called Time-toFailure tree, was presented, which can be used to accelerate the Monte Carlo simulation of fault-trees. Another application of simulations are described in [12-15].

Monte Carlo simulation is one of the most widely used simulation techniques in the field of risk management. Raychaudhuri [16] described the nature and relevance of Monte Carlo simulation, the way to perform these simulations and analyse results. The advantages of using Monte Carlo simulation against the Guide to the expression of Uncertainty Measurement (GUM) approach were outlined and discussed by Herrador and González [17]. Cox et al. [18] recommended an approach to evaluating measurement uncertainty based on the propagation of distributions using Monte Carlo simulation. Application of modelling and simulation in the decision making process was presented in [19, 20]. Rezaie et al. [21] considered the relationship of the major uncertainties of a project by using rotary algorithm intellectualized the classic Monte Carlo simulation. Kurihara and Nishiuchi [22] proposed a method to estimate network characteristics such as project time, project cost, etc. The method could estimate the network characteristics rapidly and accurately by analysing one set of Monte Carlo simulation results.

In the investment project management, the use of modern simulation techniques in risk analysis is an important element supporting the long-term success of the project. The aim of the research is to present a new approach in post-auditing of the investment project. The presented approach uses Monte Carlo simulations in combination with traditional methods, such as DEVA analysis and deviation analysis method. The results of analyses and simulations point to the critical factors influencing the project success.

\section{MATERIALS AND METHODS}

\subsection{Case study description}

The investment project "Replacement of the external distribution of central heating from boiler room K-106, northern branch" was realized during the summer months of 2013. The northern branch distribution is on an existing route with a total length of 486.70 meters. It is made of pre-insulated pipes in a non-canal line. The route is conducted in the public area, excluding interventions in privately owned plots, outside the built-up area in the public area and no demolition of aboveground objects was required. The construction was carried out in Slovakia in accordance with the Energy Act 656/2004 Coll. and the Act on thermal energy 657/2004 Coll.

The pipeline distribution replacement was necessary because of its high age (about 40 years), high risk of accidents and high heat distribution losses. Replacement of the distribution is expected to reduce the operating costs due to better thermal insulation of the pipeline distribution.

The aim of the article is to evaluate this investment project in terms of economic efficiency and risk in its implementation phase. The investment project is evaluated using the Discounted Economic Value Added (DEVA) indicator. The level of the compiled financial plan is assessed after the fourth year of its operation by the deviation analysis methods. This analysis will enable to identify the most significant risk factors and quantify their financial impact for the first four years of project operation on the value of the $D E V A_{\text {corr }}$ indicator. Taking into account the impact of risk factors for the planned period of the fifth to tenth year is realized using the Monte Carlo simulation, the output of which is a simulated $D E V A_{\text {sim }}$ financial indicator forecast. By comparison of $D E V A_{\text {corr }}$ and $D E V A_{\text {sim }}$ values with $D E V A$ 
values deviations to the plan shall be determined. These data can be used for a detailed examination of impacts of the implemented decisions, identification of the most important risk factors, saving of resources for ineffective measures and preparation of forecasts for further periods.

The process of assessment of the economic efficiency and risk of an investment project using the DEVA financial indicator is realized in three steps (see Fig. 1).

\begin{tabular}{|c|c|c|}
\hline \multirow[t]{2}{*}{ Pre-investment phase } & \multicolumn{2}{|c|}{ Investment and implementation phase } \\
\hline & $\begin{array}{l}\text { Actual (4 years } \\
\text { and } \\
\text { rected financial } \\
\text { (6 years) }\end{array}$ & $\begin{array}{c}\text { Actual (4 years) } \\
\text { and } \\
\text { simulated financial } \\
\text { plan (6 years) }\end{array}$ \\
\hline $\begin{array}{l}\text { NOPAT and Cash flow } \\
\quad(1 .-10 . \text { year })\end{array}$ & $\begin{array}{l}\text { Post-audit } \\
(1 .-4 \text { year })\end{array}$ & $\begin{array}{c}\text { Monte Carlo simulation } \\
\quad(5 .-10 \text { year })\end{array}$ \\
\hline $\begin{array}{c}\text { Investment costs } \\
\text { Revenue } \\
\text { Costs } \\
W A C C\end{array}$ & $\begin{array}{l}\text { Deviation analysis } \\
\text { methods } \\
\text { Graphical methods }\end{array}$ & $\begin{array}{c}\text { Probability distribution } \\
\text { Sensitivity chart } \\
\text { Tornado chart }\end{array}$ \\
\hline$\sqrt{2}$ & $\sqrt{2}$ & $\sqrt{3}$ \\
\hline$D E V A$ & $D E V A$ corr & $D E V A \operatorname{sim}$ \\
\hline & Deviation from $D E V A$ & \\
\hline
\end{tabular}

Figure 1: Process of assessment of the economic efficiency and risk of an investment project in its implementation phase.

\subsection{DEVA analysis}

The financial plan of the investment project is processed using a financial model created in the Microsoft Excel environment. The financial model is constructed for the life time of the project, i.e. ten years with four months construction period. The finance model includes input data from which the annual profits after tax are calculated, cash flow and dynamic financial indicator $D E V A$, profitability index and discounted payback period, by means of which the project is assessed. For the purposes of this article, only the DEVA financial indicator, the estimated value of which is EUR 229,335, is considered. The method of calculation of this financial indicator is shown in Eqs. (1) and (2) and its detailed pyramid decomposition in Fig. 2 .

$$
\begin{aligned}
D E V A & =\sum_{n=1}^{N} E V A_{n} \cdot \frac{1}{\left(1+W A C C_{n}\right)^{n}} \\
E V A_{n} & =N O P A T_{n}-C_{n-1} \cdot W A C C_{n}
\end{aligned}
$$

Where $E V A_{\mathrm{n}}$ is economic value added in year $\mathrm{n}, W A C C$ weighted average cost of capital, NOPAT net operating profit after tax, $C$ capital invested, $N$ life time of the investment and $n$ individual years of the life time of the investment.

The input parameters are:

- Investment costs. Their planned amount is EUR 275,000. They include the acquisition cost of the ISOPLUS piping system, installation and transport costs, the acquisition value of the K-106 hot water pipeline and other costs associated with elaboration of project documentation, building construction fees, and others.

- Cost of natural gas. Their calculation method is illustrated in Fig. 2. The natural gas price is multi-component. It includes, in addition to commodity prices, also payments for trader services associated with the supply, distribution and transport of gas, excise duty and a fee 
for a reserved quantity of gas, so called daily subscription maximum. The average price of natural gas is different in respective years.

- Cost of electricity. The method of calculation is illustrated in Fig. 2. The average price is also multi-component. Electricity consumption is monitored in the heat source and in the compact heat transfer station.

- Depreciations. According to the Statistical Classification of Structures (in accordance with Decree 323/2010 Coll. of the Statistical Office of the Slovak Republic), the realized project is classified under the code 2222 in the category "Local Water Pipelines". According to Income tax Act no. 595/2003 Coll. it belongs to the $5^{\text {th }}$ depreciation group with a depreciation period of 20 years. Depreciation is even.

- Revenue for sold heat. The selling price of heat is two-component, consisting of a fixed component of the maximum heat price with a reasonable profit and a variable component of the maximum heat price with excise duty. The method of their calculation is shown in Fig. 2.

The heat price since 1.1.2003 within the Slovak Republic is determined and approved by the Regulatory Office for Network Industries in Bratislava (ÚRSO). The price proposal is provided by the heat producer.

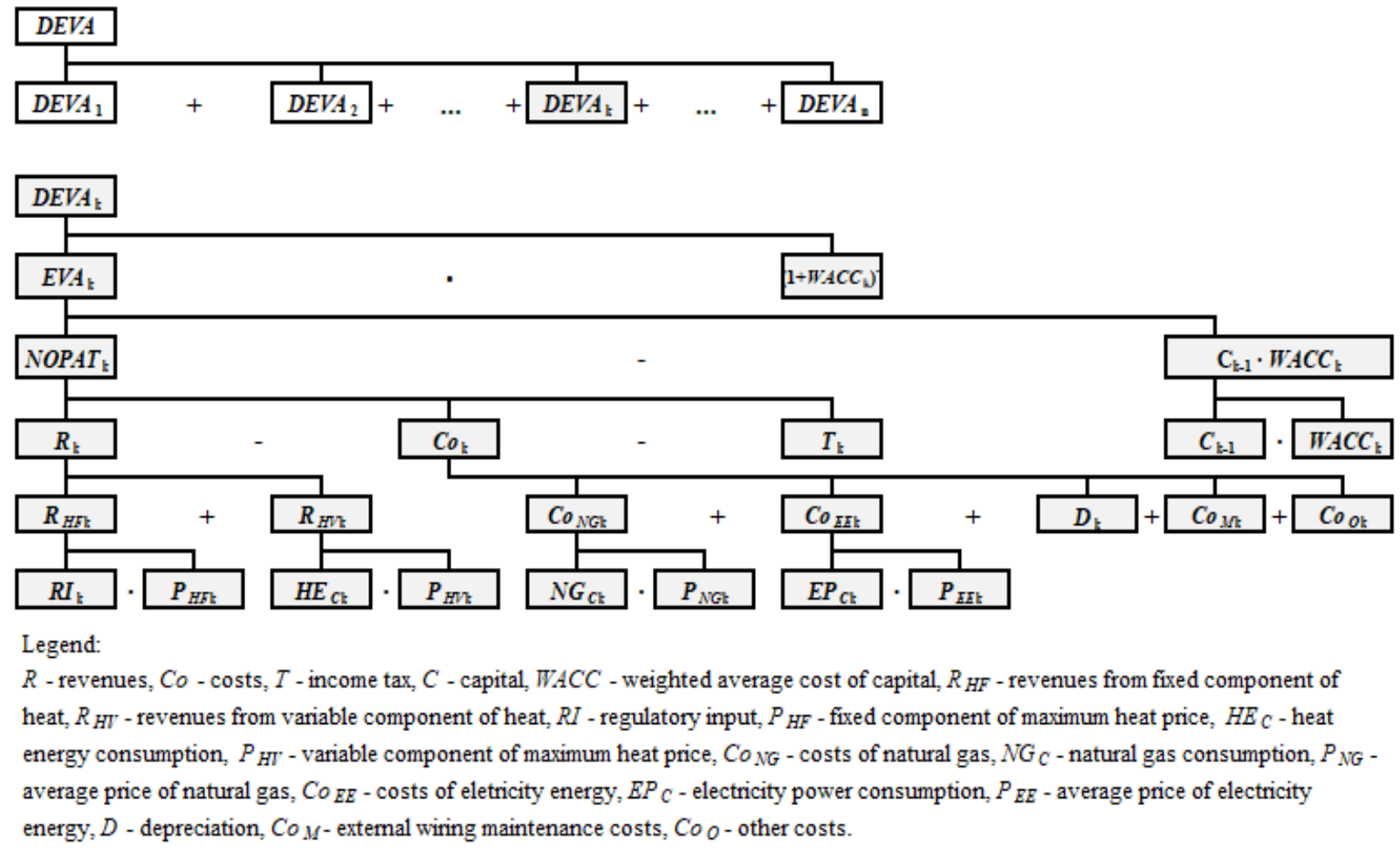

Figure 2: Pyramid decomposition of the DEVA indicator.

\subsection{Deviation analysis method}

The post-audit of the investment project is realized after the fourth year of its operation, i.e. in the period from the first to the fourth year of the project operation, the real data associated with the operation of the project are taken into account when calculating the $D E V A_{\text {corr }}$ financial indicator. For the fifth to tenth year the plan is corrected in three items. The first item is the fixed component of the maximum heat price with a reasonable profit; the second is the variable component of the maximum heat price, which for the years from 2017 to 2021 has already been approved by the Regulatory Office for Network Industries in Bratislava. The third item is the income tax rate, which fell from $22 \%$ to $21 \%$ in 2017 and is also considered 
Janekova, Fabianova, Fabian: Assessment of Economic Efficiency and Risk of the Project ...

with the same level in the next years of the project implementation. The input data for the $D E V A_{\text {corr }}$ value determination are shown in Table I.

Table I: Input data for plan (plan) and actual - corrected plan (corr).

\begin{tabular}{|c|c|c|c|c|c|c|c|c|c|c|}
\hline \multicolumn{11}{|c|}{ Variable (Unit) } \\
\hline Year & 2013 & 2014 & 2015 & 2016 & 2017 & 2018 & 2019 & 2020 & 2021 & 2022 \\
\hline \multicolumn{11}{|c|}{ Regulatory input (kWh) } \\
\hline plan & 602.0 & 590.6 & 589.2 & 589.2 & 589.2 & 589.2 & 589.2 & 589.2 & 589.2 & 589.2 \\
\hline corr & 602.0 & 590.6 & 589.2 & 589.2 & 589.2 & 589.2 & 589.2 & 589.2 & 589.2 & 589.2 \\
\hline \multicolumn{11}{|c|}{ Fixed component of maximum heat price (EUR/kWh) } \\
\hline plan & 187.514 & 194.080 & 200.870 & 207.900 & 213.180 & 213.180 & 213.180 & 217.180 & 217.180 & 217.180 \\
\hline corr & 187.514 & 209.545 & 209.545 & 209.545 & 229.743 & 229.743 & 229.743 & 229.743 & 229.743 & 229.743 \\
\hline \multicolumn{11}{|c|}{ Heat energy consumption (kWh) } \\
\hline plan & $3,101,901$ & $3,053,510$ & $3,006,084$ & $3,052,075$ & $2,914,059$ & $2,914,059$ & $2,914,059$ & $2,914,059$ & $2,914,059$ & $2,914,059$ \\
\hline corr & $3,178,528$ & $2,751,505$ & $2,873,340$ & $\mathbf{3 , 0 3 5 , 2 2 7}$ & $2,914,059$ & $2,914,059$ & $2,914,059$ & $2,914,059$ & $2,914,059$ & $2,914,059$ \\
\hline \multicolumn{11}{|c|}{ Variable component of maximum heat price (EUR/kWh) } \\
\hline plan & 0.055 & 0.055 & 0.055 & 0.055 & 0.056 & 0.056 & 0.056 & 0.057 & 0.057 & 0.057 \\
\hline corr & 0.055 & 0.0506 & 0.0506 & 0.0506 & 0.04 & 0.04 & 0.04 & 0.04 & 0.04 & 0.04 \\
\hline \multicolumn{11}{|c|}{ Natural gas consumption (kWh) } \\
\hline plan & $4,315,107$ & $4,204,284$ & $4,010,757$ & $3,686,931$ & $3,947,126$ & $3,947,126$ & $3,947,126$ & $3,947,126$ & $3,947,126$ & $3,947,126$ \\
\hline corr & $4,334,579$ & $3,598,553$ & $3,767,963$ & $3,895,945$ & $3,947,126$ & $3,947,126$ & $3,947,126$ & $3,947,126$ & $3,947,126$ & $3,947,126$ \\
\hline \multicolumn{11}{|c|}{ Average prices of natural gas (EUR/kWh) } \\
\hline plan & 0.035 & 0.036 & 0.038 & 0.039 & 0.04 & 0.04 & 0.04 & 0.04 & 0.04 & 0.04 \\
\hline corr & 0.035 & $\mathbf{0 . 0 3 7}$ & $\mathbf{0 . 0 3 5}$ & 0.035 & 0.04 & 0.04 & 0.04 & 0.04 & 0.04 & 0.04 \\
\hline \multicolumn{11}{|c|}{ Electricity power consumption (kWh) } \\
\hline plan & 57,500 & 57,500 & 57,500 & 57,500 & 57,500 & 57,500 & 57,500 & 57,500 & 57,500 & 57,500 \\
\hline corr & 59,499 & 59,379 & 62,407 & $\mathbf{5 7 , 8 5 5}$ & 57,500 & 57,500 & 57,500 & 57,500 & 57,500 & 57,500 \\
\hline \multicolumn{11}{|c|}{ Average price of electricity energy (EUR/kWh) } \\
\hline plan & 0.191 & 0.198 & 0.204 & 0.212 & 0.219 & 0.219 & 0.219 & 0.219 & 0.219 & 0.219 \\
\hline corr & 0.185 & 0.188 & $\mathbf{0 . 1 8 5}$ & 0.185 & 0.219 & 0.219 & 0.219 & 0.219 & 0.219 & 0.219 \\
\hline \multicolumn{11}{|c|}{ External wiring maintenance costs (EUR) } \\
\hline plan & 5,000 & 0 & 0 & 0 & 5,000 & 0 & 0 & 0 & 5,000 & 0 \\
\hline corr & 7,000 & $\mathbf{0}$ & $\mathbf{0}$ & $\mathbf{0}$ & 5,000 & 0 & 0 & 0 & 5,000 & 0 \\
\hline \multicolumn{11}{|c|}{ Other costs (EUR) } \\
\hline plan & 30,000 & 30,000 & 30,000 & 30,000 & 30,000 & 30,000 & 30,000 & 30,000 & 30,000 & 30,000 \\
\hline corr & 27,452 & 25,436 & 24,765 & 28,675 & 30,000 & 30,000 & 30,000 & 30,000 & 30,000 & 30,000 \\
\hline \multicolumn{11}{|c|}{ Depreciation (EUR) } \\
\hline plan & 13,750 & 13,750 & 13,750 & 13,750 & 13,750 & 13,750 & 13,750 & 13,750 & 13,750 & 13,750 \\
\hline corr & 14,000 & 14,000 & 14,000 & 14,000 & 14,000 & 14,000 & 14,000 & 14,000 & 14,000 & 14,000 \\
\hline \multicolumn{11}{|c|}{ Income tax $(\%)$} \\
\hline plan & 23 & 22 & 22 & 22 & 22 & 22 & 22 & 22 & 22 & 22 \\
\hline corr & 23 & 22 & 22 & 22 & 21 & 21 & 21 & 21 & 21 & 21 \\
\hline \multicolumn{11}{|c|}{$W A C C(\%)$} \\
\hline plan & $\mathbf{1 0}$ & 10 & $\mathbf{1 0}$ & $\mathbf{1 0}$ & 10 & 10 & 10 & 10 & 10 & 10 \\
\hline corr & 10 & 10 & $\mathbf{1 0}$ & $\mathbf{1 0}$ & 10 & 10 & 10 & 10 & 10 & 10 \\
\hline \multicolumn{11}{|c|}{ Invested capital (EUR) } \\
\hline plan & 275,000 & 261,250 & 247,500 & 233,750 & 220,000 & 206,250 & 192,500 & 178,750 & 165,000 & 151,250 \\
\hline corr & 280,000 & 266,000 & 252,000 & 238,000 & 224,000 & 210,000 & 196,000 & 182,000 & 168,000 & 154,000 \\
\hline
\end{tabular}

The goal of the post-audit is to identify, by means of deviation analysis methods, risk factors that most affected the size of $D E V A_{\text {corr }}$ variance, determined as the difference between the $D E V A_{\text {corr }}$ value and the predicted $D E V A$ value. The choice of method is determined by the structure of pyramid decomposition of the analysed (synthetic) DEVA indicator (see Fig. 2), in particular by the links that exist between the partial (analytical) indicators. For additive relations, the quantification of the influence of determinant elements is performed using the simple decomposition method. The quantification of impact in multiplicative relations is more 
complicated than in additive relations. This means that if, in case of additive relations, it is true that $\Delta x=\Delta a \pm \Delta b$, in case of multiplicative relation the relationship is not analogous equal, thus $\Delta x \neq \Delta a \cdot \Delta b$ (or $\Delta x \neq \Delta a \div \Delta b$ ), whereby $\Delta x$ is absolute change of the synthetic indicator $x$, and $\Delta a$ and $\Delta b$ are absolute changes of the analytical indicators $a, b$. For both relations, it is true that the change of the synthetic indicator is always given by the sum of the changes of the analytical indicators, no matter what type of relation is between the analytical indicators. In multiplicative relations, a functional method is applied, which is referred to as accurate, algorithmically more complex, especially in the case of several analytical factors, however always applicable.

\subsection{Monte Carlo simulation}

Simulations are performed using the Monte Carlo technique. The technique is based on random sampling of values from input variables probability distributions and calculation of the output according to the given formula. In this way, the probability distribution of inputs is projected into the output variable. The distribution function and its statistical characteristics are defined for each input variable (see Table II). The reliability of simulation results depends on proper estimates and the number of random generations. In our case, 10,000 generations are carried out.

Table II: Distribution functions and statistical characteristics of input variables.

\begin{tabular}{|c|c|c|c|c|}
\hline \multicolumn{2}{|r|}{ Variable } & Unit & Statistical characteristics & $\begin{array}{l}\text { Distribution } \\
\text { function }\end{array}$ \\
\hline \multirow{4}{*}{ 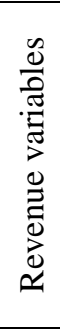 } & Regulatory input & $\mathrm{kWh}$ & $\begin{array}{l}\text { Likeliest 589.20; Min. 585; } \\
\text { Max. } 610\end{array}$ & BetaPERT \\
\hline & $\begin{array}{l}\text { Fixed component of maximum } \\
\text { heat price }\end{array}$ & $\mathrm{EUR} / \mathrm{kWh}$ & $\begin{array}{l}\text { Mean 229.74; Min. 210; } \\
\text { Max. 229.74 }\end{array}$ & Triangular \\
\hline & $\begin{array}{l}\text { Variable component of } \\
\text { maximum heat price }\end{array}$ & EUR/kWh & $\begin{array}{l}\text { Mean 0.04; Min. 0.03; } \\
\text { Max. 0.04 }\end{array}$ & Triangular \\
\hline & Heat energy consumption & $\mathrm{kWh}$ & $\begin{array}{c}\text { Likeliest 2,914,059; Min. } \\
\text { 2,600,000; Max. 3,200,000 }\end{array}$ & BetaPERT \\
\hline \multirow{8}{*}{ 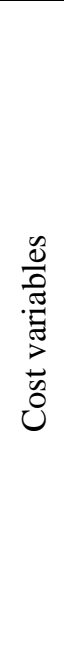 } & Natural gas consumption & $\mathrm{kWh}$ & Likeliest 4.3; Min. 4; Max. 4.6 & BetaPERT \\
\hline & Average price of natural gas & $\mathrm{EUR} / \mathrm{kWh}$ & $\begin{array}{l}\text { Likeliest 0.04; Min. 0.04; } \\
\text { Max. 0.05 }\end{array}$ & BetaPERT \\
\hline & Electricity power consumption & $\mathrm{kWh}$ & $\begin{array}{c}\text { Likeliest 57,500; Min. 51,750; } \\
\text { Max. 63,250 }\end{array}$ & BetaPERT \\
\hline & $\begin{array}{l}\text { Average price of electricity } \\
\text { energy }\end{array}$ & EUR/kWh & $\begin{array}{l}\text { Mean 0.22; Min. 0.19; } \\
\text { Max. } 0.23\end{array}$ & Triangular \\
\hline & Other costs & EUR & $\begin{array}{c}\text { Mean 30,000; Min. 27,000; } \\
\text { Max. 33,000 }\end{array}$ & Triangular \\
\hline & Income tax & coeff. & $\begin{array}{l}\text { Value } 0.21 \text {; Probability } 0.5 ; \\
\text { Value } 0.20 \text {; Probability } 0.3 ; \\
\text { Value } 0.19 \text {; Probability } 0.2\end{array}$ & Discrete \\
\hline & WACC & coeff. & $\begin{array}{l}\text { Mean 0.10; Min 0.09; } \\
\text { Max. 0.11 }\end{array}$ & Triangular \\
\hline & Invested capital & EUR & $\begin{array}{l}\text { Location 270,000; } \\
\text { Mean 280,000; Std. Dev. 5,000 }\end{array}$ & Lognormal \\
\hline
\end{tabular}

\section{RESULTS}

\subsection{Deviation analysis results}

Based on data from Table I it can be seen that the first years of the project implementation indicate the development of key variables in negative direction. The post-audit performed 
after four years of investment operation only confirmed these changes and helped to identify sources of the most serious deviations of the actual development compared to the plan. Applying the deviation analysis methods (see Section 2.3) there are quantified the total impacts of each analytical indicator (see Fig. 2) on the resulting deviation value of $D E V A_{\text {corr }}$, including the effects in terms of time.

It is already possible to declare that the financial plan of the investment project was very optimistic because it assumed DEVA at EUR 229,335 for a period of ten years. The calculated value of $D E V A_{\text {corr }}$ is EUR 145,834, thus the $D E V A_{\text {corr }}$ absolute deviation is EUR $(-83,501)$, representing a decrease of $36.41 \%$ from the projected $D E V A$ value.

Deviation of $D E V A_{\text {corr }}$ is caused mainly due to deviations of variables determining revenue and costs. The total value of deviation for the ten year period most positively affected the increase of the fixed component of the maximum heat price, the decrease of the income tax rate, negatively the decrease of the variable component of maximum heat price, the increase of the average price of natural gas and the fluctuating development of natural gas consumption (see Table III).

Table III: Total impacts of the most important analytical indicators on the deviation $D E V A_{\text {corr }}$.

\begin{tabular}{|l|c|c|}
\hline \multicolumn{1}{|c|}{ Variable } & $\begin{array}{c}\text { Absolut impact } \\
(\text { EUR })\end{array}$ & $\begin{array}{c}\text { Relative impact } \\
(\%)\end{array}$ \\
\hline Fixed component of maximum heat price & 38,073 & 16.60 \\
\hline Heat energy consumption & $-15,221$ & -6.64 \\
\hline Variable component of maximum heat price & $-171,834$ & -74.92 \\
\hline Natural gas consumption & 19,029 & 8.29 \\
\hline Average price of natural gas & 23,982 & 10.46 \\
\hline Other costs & 10,926 & 4.76 \\
\hline Income tax & 24,163 & 10.54 \\
\hline Other variables & $-12,619$ & -5.50 \\
\hline Deviation of $\boldsymbol{D E V A}_{\text {corr }}$ (total) & $\mathbf{- 8 3 , 5 0 1}$ & $\mathbf{- 3 6 . 4 1}$ \\
\hline
\end{tabular}

\subsection{Simulation results}

The corrected indicator $D E V A_{\text {corr }}$ is closer to the fair value but cannot be considered reliable. The 6-year period is a very long period in terms of change of market variables, such as sale and purchase prices, sold and purchased amount, as well as climatic conditions, which are as uncertain as market variables. These uncertainties can be defined by an appropriate distribution and probability characteristics on the basis of the known historical data and qualified estimation. Then, using the Monte Carlo simulation, a forecast of DEVA indicator $\left(D E V A_{\text {sim }}\right)$ with its probabilistic profile can be derived. Based on that, an enterprise can take preventive actions against unwanted developments.

The result of simulation also shows that the expected economic efficiency of the investment was too optimistic. By comparing $D E V A_{\text {corr }}$ and the mean value of $D E V A_{\text {sim }}$, we can see that $D E V A_{\text {corr }}\left(\right.$ EUR 145,834) is well above $D E V A_{\text {sim }}$ (EUR 116,416). The probability that DEVA will be not above the value of EUR 145,834 is about $82 \%$ (see Fig. 3).

Forecast accuracy is affected by the uncertainties of all input variables. Some contribute more than the others to the overall uncertainty of the forecast, some contribute less, depending on the distribution and strength of their influence on the final financial criterion. The simulation outputs provide a report in the form of sensitivity chart and tornado chart (see Figs. 4 and 5). 


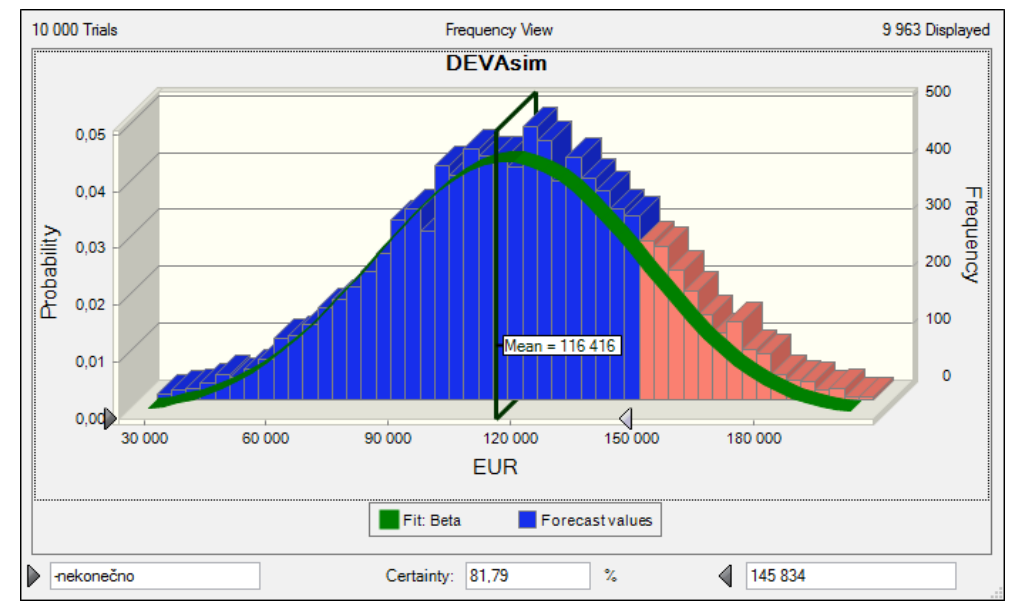

Figure 3: Forecast of the DEVA indicator.

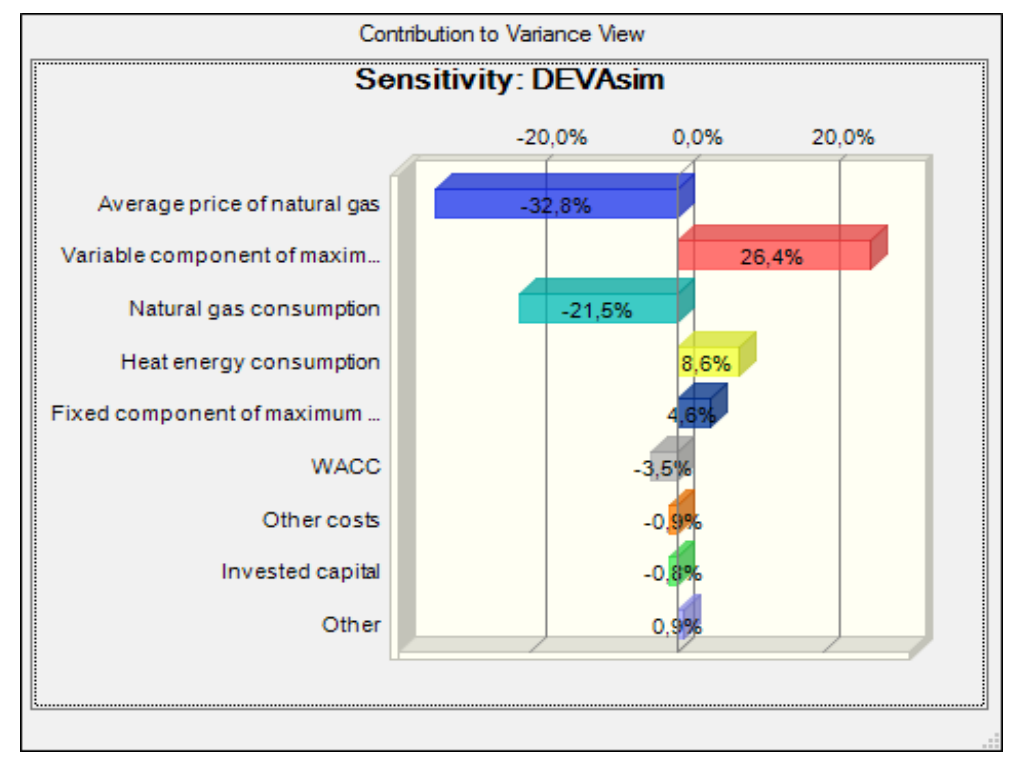

Figure 4: Sensitivity chart of DEVA indicator.

The sensitivity chart informs about the impact of the variables uncertainties and their contribution to the overall uncertainty of the DEVA indicator. We are able to clearly identify key variables in terms of the overall uncertainty of the forecast, and we also know the nature of their impact, whether they increase or reduce $D E V A$, i.e. whether they are cost or revenue variables (see Fig. 4). From the sensitivity chart, it is obvious that uncertainty of the average price of natural gas contributes by $32.8 \%$ to the total variance, and it is a variable that reduces the value of DEVA.

The tornado chart gives a picture about the power of the individual variable on the DEVA indicator. The tornado chart does not consider real occurrence of the change, whether the change is only positive or negative and to what extent can occur. The chart shows the variables according to their influence in the defined range of their changes, in both positive and negative direction. The tornado chart (see Fig. 5) shows the variables ordered by the size of their impact on the DEVA indicator, at the assumed variation $\pm 10 \%$. The variables that have shown in deviation analysis little effect on the DEVA indicator are excluded from the tornado chart. This is due to the elimination of non-essential information from the chart. In the tornado chart, average price of natural gas along with natural gas consumption emerged as potentially the most serious factors causing the deviation of DEVA from the planned value. Their priority of risk factors is also confirmed by sensitivity analysis. 


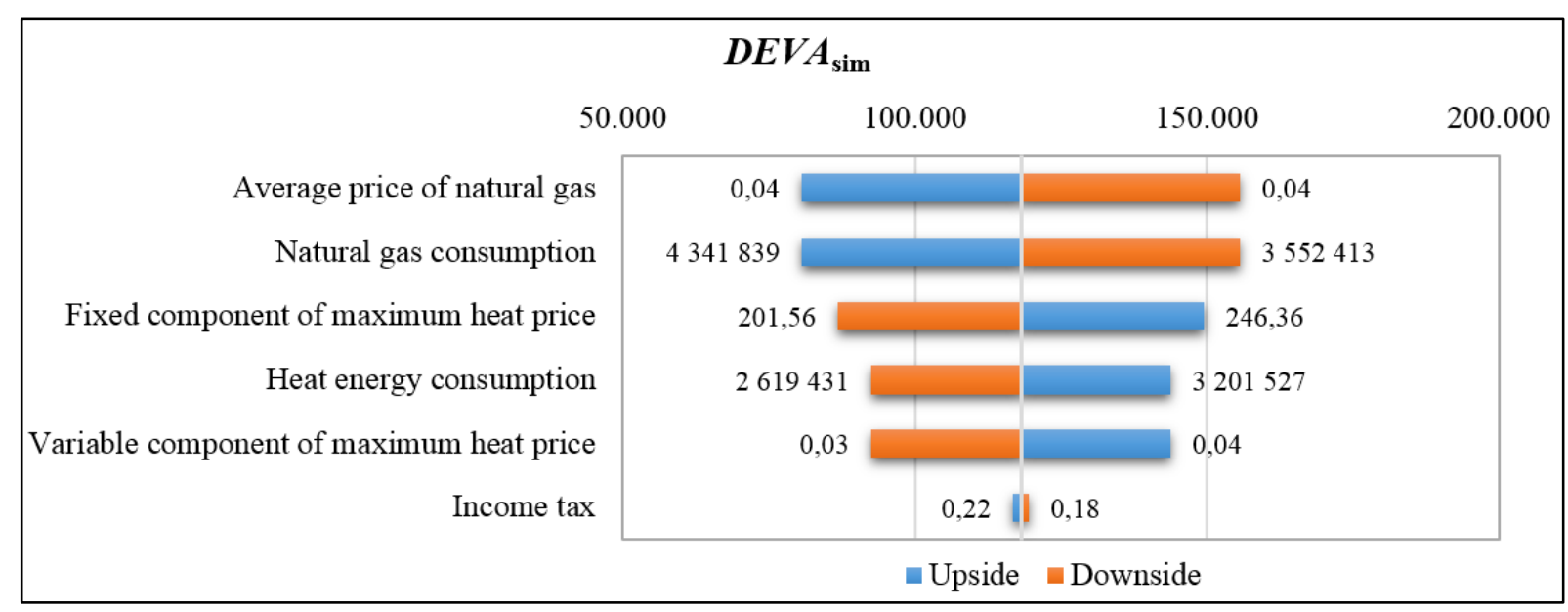

Figure 5: Tornado chart of DEVA indicator.

The correlation analysis shows the statistical dependence between the DEVA indicator and the input variables. There was no substantial correlation $(p>0.8)$ in any of the input variables. A slight negative correlation is between $D E V A$ and the variables: average price of natural gas (-0.5203) and natural gas consumption (-0.4035). A slight positive correlation is in relation to the variable component of the maximum heat price $(0.4555)$. Other variables showed a low correlation to DEVA $(p<0.3)$.

The above-presented simulation analysis in combination with the deviation analysis allow a company to focus its attention on the important factors that determine the change of the $D E V A$ indicator. Among the factors are factors controllable more, others less or not at all. The enterprise can use this information to aim measures at the factors that can be regulated (e.g., the fixed and variable heat price component), or take action to compensate the impact of unregulated variables (e.g., the amount of heat energy consumption depending on climatic conditions and the number of customers). Thus, the company is actively involved in managing the economic efficiency of the investment.

\section{CONCLUSIONS}

\subsection{Discussion and research implications}

Forecasting of economic efficiency of investments is still associated with risks because the development of market variables is characterized by high variability. The estimation of many parameters is for a long time period, often 10-20 years. The issue of investment risk management can be of strategic importance to an enterprise. In case of financially demanding projects, mistakes could lead to the loss of economic stability of the company. In practice, mostly dynamic methods that use discounted variables are used for project risk assessment.

The study aimed to present an approach to assessment of economic efficiency and risk of the investment project in its implementation phase. In this case study, post-audit was presented after $4^{\text {th }}$ year of investment implementation. The minimum lifetime was planned to be 10 years. A multilevel post-audit was conducted by economic efficiency assessment (using the DEVA financial indicator) in combination with the Monte Carlo simulation technique. In the first phase of investment project assessment, based on the deviation analysis, the most serious factors causing DEVA deviation from the planned value were identified. Subsequently, corrections were made for selected input variables, and the corrected indicator $D E V A_{\text {corr }}$ was calculated. Uncertainties of the input variables were defined according to their development in the previous 4 years, as well as on the basis of the now known values (e.g., upper limits of regulated quantities determined by the Regulatory Office for Network 
Industries). Forecast of the DEVA indicator $\left(D E V A_{\text {sim }}\right)$ was conducted by Monte Carlo simulation for 10 years, and also further analyses were performed. The values and deviations of the DEVA indicator are presented in Table IV.

Table IV: Values and deviations of the DEVA indicator.

\begin{tabular}{|l|c|c|c|c|c|}
\hline \multirow{2}{*}{ Indicator } & \multirow{2}{*}{$\begin{array}{c}\text { Value } \\
\text { (EUR) }\end{array}$} & \multicolumn{2}{c|}{ Deviation from $\boldsymbol{D E \boldsymbol { E } \boldsymbol { A }}$} & \multicolumn{2}{c|}{ Deviation from $\boldsymbol{D E} \boldsymbol{V} \boldsymbol{A}_{\text {corr }}$} \\
\cline { 3 - 6 } & 229,335 & - & $(\%)$ & $($ EUR $)$ & $(\%)$ \\
\hline$D E V A$ & 145,834 & $-83,501$ & - & - & - \\
\hline$D E V A_{\text {corr }}$ & 116,416 & $-112,919$ & -36.41 & - & - \\
\hline$D E V A_{\text {sim }}$ (mean value) & & -49.23 & $-29,418$ & -20.17 \\
\hline
\end{tabular}

The impact of variables uncertainty on the DEVA indicator uncertainty was examined by sensitivity analysis. Tornado chart showed how individual changes of each variable could be reflected in the change of $D E V A$. For the purpose of assessing the economic efficiency of the investment, it is of course possible to use another financial indicator than DEVA; e.g., Net Present Value $(N P V)$ or Economic Value Added (EVA). Some scientific work applied Monte Carlo simulations in conjunction with other indicators, for example $N P V$ was used by Holopainen et al. [23] or EVA by Borgonovo and Peccati [24]. Also, researchers used Monte Carlo simulation in solving other problems - e.g., prediction of market shares under varying market conditions [25] or evaluation of the measurement uncertainty [17]. Some of them conducted risk analysis only in a selected form; e.g., by sensitivity analysis [24] or by consideration of relationships between uncertainties [21]. In the above presented research study, a holistic approach in post-auditing covering the use of standard dynamic methods in combination with simulation and risk analysis, has been introduced. Thus, the results are benefits and expand the theoretical knowledge base used in project management. The data from the simulation provide to the company further important information needed in decisionmaking.

When implementing the presented post-audit model, it should be kept in mind that the uncertainty of each variable is reflected in the uncertainty of the resulting indicator. Therefore, it is important to define the uncertainty of the input variables only where it is justified and really important. As far as possible, the uncertainty should be predicted for the shortest possible time for accuracy. For long-term investments, it is appropriate to carry out the post-audit at regular 1-2 year intervals to update the uncertainty of variables and reviewed the efficiency of the measures.

Another possible way of using this methodology is to apply it retrospectively. Thus, to compare the actual efficiency of the investment with the simulated one, after a certain period of its operation. By performing simulation of the impacts of measures that could be applied but were not, we could gain further insight into the applicability and significance of simulations in project management.

\subsection{Limitations and future research directions}

Although the Monte Carlo simulation provides valuable information on future developments, it is not a universal tool that can be used without securing additional aspects of reliability. Knowledge of simulation tools and their application in project risk management will not solve anything by itself; it is just one aspect of successful management of economic efficiency of the investment. A greater weight is given to an expert who performs these analyses, his professional competence and the ability to think within a broader context.

In this case study, when forecasting the values of input variables, the forecast was based only on the last 4-year period of operation, which is a short time for a reliable forecast. We 
simplified this approach because of priority to present the methodology of post-audit using simulation and not to achieve the maximum accuracy of the results.

This research did not consider the regression relationship between the individual input variables that exists in the real market environment (e.g., price and sold amount). This fact was not taken into account because heat is a very specific article where these basic market variables are not as closely related as in consumer goods. Heat consumption is mainly due to climatic reasons, and consumers cannot substitute the product in case of dissatisfaction. In future research focusing on another type of investment, it would be appropriate to define this relationship with a reasonable correlation.

\section{ACKNOWLEDGEMENT}

This work has been supported by grant projects VEGA No. 1/0110/18 "Research and development in the area of reverse engineering and rapid prototyping focused on innovations of constructional parts designed for the experimental vehicles and transport equipment", and KEGA 030TUKE-4/2017 "Implementation of innovative tools to improve the quality of university education in the field of study 5.2.52 Industrial Engineering".

\section{REFERENCES}

[1] Denić, N.; Moračanin, V.; Milić, M.; Nešić, Z. (2014). Risk management in information system projects, Technical Gazette, Vol. 21, No. 6, 1239-1242

[2] Azzone, G.; Maccarrone, P. (2001). The design of the investment post-audit process in large organisations: evidence from a survey, European Journal of Innovation Management, Vol. 4, No. 2, 73-87, doi:10.1108/14601060110390567

[3] Soares, J. O.; Coutinho, M. C.; Martins, C. V. (2007). Forecasting errors in capital budgeting: A multi-firm post-audit study, The Engineering Economist, Vol. 52, No. 1, 21-39, doi: 10.1080/00137910601159771

[4] Sandström, J.; Kyläheiko, K.; Collan, M. (2016). Managing uncertainty in long life cycle investments: unifying investment planning, management, and post-audit with a fuzzy DSS, International Journal of Business Innovation and Research, Vol. 11, No. 1, 133-145, doi:10.1504/IJBIR.2016.077613

[5] Janeková, J.; Fabianová, J.; Onofrejová, D.; Puškáš, E.; Buša, M. (2017). Implementation of deviation analysis method in the utilisation phase of the investment project: a case study, Polish Journal of Management Studies, Vol. 15, No. 1, 99-109, doi:10.17512/pjms.2017.15.1.10

[6] Lendo-Siwicka, M.; Połoński, M.; Pawluk, K. (2016). Identification of the interference in the investment process during the realization of a shopping centre - a case study, Archives of Civil Engineering, Vol. 62, No. 1, 159-172, doi:10.1515/ace-2015-0058

[7] Suresh, P. V.; Babar, A. K.; Raj, V. V. (1996). Uncertainty in fault tree analysis: A fuzzy approach, Fuzzy Sets and Systems, Vol. 83, No. 2, 135-141, doi:10.1016/0165-0114(95)00386-X

[8] Bucci, P.; Kirschenbaum, J.; Mangan, L. A.; Aldemir, T.; Smith, C.; Wood, T. (2008). Construction of event-tree/fault-tree models from a Markov approach to dynamic system reliability, Reliability Engineering \& System Safety, Vol. 93, No. 11, 1616-1627, doi:10.1016/j.ress.2008.01.008

[9] Durga Rao, K.; Gopika, V.; Sanyasi Rao, V. V. S.; Kushwaha, H. S.; Verma, A. K.; Srividya, A. (2009). Dynamic fault tree analysis using Monte Carlo simulation in probabilistic safety assessment, Reliability Engineering \& System Safety, Vol. 94, No. 4, 872-883, doi:10.1016/j.ress.2008.09.007

[10] Ferdous, R.; Khan, F.; Veitch, B.; Amyotte, P. R. (2009). Methodology for computer aided fuzzy fault tree analysis, Process Safety and Environmental Protection, Vol. 87, No. 4, 217-226, doi:10.1016/j.psep.2009.04.004

[11] Ejlali, A.; Miremadi, S. G. (2004). FPGA-based Monte Carlo simulation for fault tree analysis, Microelectronics Reliability, Vol. 44, No. 6, 1017-1028, doi:10.1016/j.microrel.2004.01.016 
[12] Fedorko, G.; Rosová, A.; Molnár, V. (2014). The application of computer simulation in solving traffic problems in the urban traffic management in Slovakia, Theoretical and Empirical Researches in Urban Management, Vol. 9, No. 3, 15-17

[13] Neradilová, H.; Fedorko, G. (2016). The use of computer simulation methods to reach data for economic analysis of automated logistic systems, Open Engineering, Vol. 6, No. 1, 700-710, doi:10.1515/eng-2016-0085

[14] Straka, M.; Malindzakova, M.; Trebuna, P.; Rosova, A.; Pekarcikova, M.; Fill, M. (2017). Application of EXTENDSIM for improvement of production logistics' efficiency, International Journal of Simulation Modelling, Vol. 16, No. 3, 422-434, doi:10.2507/IJSIMM16(3)5.384

[15] Šaderová, J.; Kačmáry, P. (2013). The simulation model as a tool for the design of number of storage locations in production buffer store, Acta Montanistica Slovaca, Vol. 18, No. 1, 33-39

[16] Raychaudhuri, S. (2008). Introduction to Monte Carlo simulation, Proceedings of the 2008 Winter Simulation Conference, 91-100, doi:10.1109/WSC.2008.4736059

[17] Herrador, Á. M.; González, G. A. (2004). Evaluation of measurement uncertainty in analytical assays by means of Monte-Carlo simulation, Talanta, Vol. 64, No. 2, 415-422, doi: $10.1016 / j . t a l a n t a .2004 .03 .011$

[18] Cox, M.; Harris, P.; Siebert, B. R.-L. (2003). Evaluation of measurement uncertainty based on the propagation of distributions using Monte Carlo simulation, Measurement Techniques, Vol. 46, No. 9, 824-833, doi:10.1023/B:METE.0000008439.82231.ad

[19] Irujo, J. A.; Pérez-Ezcurdia, M. A. (2017). Understanding top management's decision-making on implementing project management systems - an exploratory study, Technical Gazette, Vol. 24, No. 3, 837-846, doi:10.17559/TV-20160229114224

[20] Janekova J.; Fabianova J.; Izarikova G.; Onofrejova, D.; Kovac, J. (2018). Product mix optimization based on Monte Carlo simulation: a case study, International Journal of Simulation Modelling, Vol. 17, No. 2, 295-307. doi:10.2507/IJSIMM17(2)436

[21] Rezaie, K.; Amalnik, M. S.; Gereie, A.; Ostadi, B.; Shakhseniaee, M. (2007). Using extended Monte Carlo simulation method for the improvement of risk management: Consideration of relationships between uncertainties, Applied Mathematics and Computation, Vol. 190, No. 2, 1492-1501, doi:10.1016/j.amc.2007.02.038

[22] Kurihara, K.; Nishiuchi, N. (2002). Efficient Monte Carlo simulation method of GERT-type network for project management, Computers \& Industrial Engineering, Vol. 42, No. 2-4, 521531, doi:10.1016/S0360-8352(02)00050-5

[23] Holopainen, M.; Mäkinen, A.; Rasinmäki, J.; Hyytiäinen, K.; Bayazidi, S.; Pietilä, I. (2010). Comparison of various sources of uncertainty in stand-level net present value estimates, Forest Policy and Economics, Vol. 12, No. 5, 377-386, doi:10.1016/j.forpol.2010.02.009

[24] Borgonovo, E.; Peccati, L. (2004). Sensitivity analysis in investment project evaluation, International Journal of Production Economics, Vol. 90, No. 1, 17-25, doi:10.1016/S09255273(03)00213-5

[25] Chakraborty, G.; Ball, D.; Gaeth, G. J.; Jun, S. (2002). The ability of ratings and choice conjoint to predict market shares: a Monte Carlo simulation, Journal of Business Research, Vol. 55, No. 3, 237-249, doi:10.1016/S0148-2963(00)00127-2 